\title{
Megaminería en México en el contexto de América Central
}

\section{Federico Guzmán López*}

Resumen. El proyecto extractivo de la megaminería en México fue impulsado desde la década de 1980 por empresarios mineros y el Gobierno federal. El propósito fue generar inversiones y fuentes de empleo, así como incrementar la valorización del capital a través de megaproyectos transnacionales de minería a cielo abierto, vinculados a cadenas de valor global, bajo el dominio del capital financiero, extractivo y proveedor. Resulta pertinente analizar la relevancia de la megaminería desde la perspectiva teórica de la ecología política y la economía ecológica sobre los temas de justicia ambiental y derechos humanos que generan desigualdades en territorios como México, en el contexto ampliado hacia América Central. Los resultados indican que la megaminería convirtió a México en el espacio más sacrificado de la región extendida a Centroamérica, mediante una dinámica de despojo territorial en cuanto al agotamiento de los recursos naturales, mayor concentración de tierras, pobreza, corrupción, derechos humanos vulnerados y conflictos socioambientales.

Palabras clave: conflictos socioambientales, despojo territorial, derechos humanos, extractivismo, intercambio desigual.

* Colaborador del Atlas de Justicia Ambiental (EJAtlas), doctor en Estudios del Desarrollo, Universidad Autónoma de Zacatecas «Francisco García Salinas» y posdoctorante del Consejo Nacional de Ciencia y Tecnología (Conacyt) del Gobierno de México, en el Doctorado en Ciencias Agrarias, Universidad Autónoma Chapingo. Correo-e: federic7@hotmail.com 


\section{Megamining in Mexico in the Central American context}

Abstract. The megamining extractive project in Mexico has been driven since the 1980s by mining companies and the federal government. The goal was to create investments and employment, as well as grow profits, through transnational openpit megaprojects, tied to the global value chains, under the control of financial, extractive and investment capital. It is worth analyzing the role of megamining, which generates inequalities in territories such as Mexico in the Central American context, from the theoretical perspective of political ecology and ecological economics, on topics of environmental justice and human rights. The results point to megamining having converted Mexico into the most exploited region of Central America, through a dynamic of land dispossession, the depletion of natural resources, increased concentration of land ownership, poverty, corruption, human rights violations and socio-environmental conflicts.

Keywords: socio-environmental conflicts, land dispossession, human rights, extractivism, unequal exchange. 


\section{Introducción}

En México son pocos los espacios nacionales de pensamiento crítico dedicados al diálogo y análisis de la dinámica ecosocial de la megaminería, que ha puesto en entredicho la justicia ambiental y la salvaguarda de los derechos humanos durante los 37 años del periodo neoliberal y con mayor intensidad en lo que va de las dos primeras décadas del siglo XXI. Esta cuestión significa un problema agrario emergente con estrecha vinculación al desarrollo nacional, que ha tenido poca atención por los científicos sociales y de las humanidades; por ello la pertinencia de estudiarlo desde la perspectiva teórica de la economía ecológica y la ecología política.

El objetivo del presente artículo es analizar el nexo entre megaminería, justicia ambiental y derechos humanos en el desarrollo de México en el contexto ampliado a América Central para fines analíticos, lo que permite incluir en el análisis a las naciones de Belice, Costa Rica, El Salvador, Guatemala, Honduras, Nicaragua y Panamá, a partir de su génesis e impactos, durante el periodo 1982-2019, referente a la fase neoliberal del sistema capitalista dominante a escala global.

Se argumenta que la megaminería practicada en el territorio mexicano, que tiene como soporte la extracción, beneficio y comercialización de metales preciosos durante el periodo neoliberal, ha tenido como propósito central generar y transferir la renta minera en beneficio de las redes de capital global, conformadas por el capital financiero, extractivo y proveedor. Lo anterior en perjuicio de las comunidades aledañas donde se instalan los megaproyectos mineros, lo que generó afectaciones ambientales y vulneración de los derechos humanos. Sin embargo, las acciones colectivas de resistencia 


\section{FEDERICO GUZMÁN LóPEZ}

que se han tejido, en lugar de cuestionar de manera crítica dicha dinámica, se reducen principalmente a ejercer presión social ante las empresas mineras como mecanismo para acceder a un mayor reparto de la renta minera.

El contexto global-local en que se inscribe este estudio se distingue por la existencia de una crisis de escala planetaria y multidimensional que abarca las esferas alimentaria, climática, económica, energética, financiera, laboral y política, ${ }^{1}$ acompañado por el fenómeno del acaparamiento de tierras y agua del planeta, que benefició fundamentalmente al capital financiero y extractivo transnacional, y sobre todo a aquellos corporativos privados que encontraron nuevos nichos de valorización del capital en las cadenas de valor global de los alimentos, agua y minerales.

Asimismo, a escala global estamos avanzando en la transición de la matriz productiva y energética, donde el siglo XX y particularmente los 37 años del periodo neoliberal del sistema de producción capitalista se distinguieron por la dependencia de combustibles fósiles, al igual que por la explotación, beneficio y consumo de metales preciosos. A lo largo de las dos primeras décadas del siglo XXI se observa una tendencia gradual orientada hacia el predominio de los minerales no metálicos, especialmente de las tierras raras, ${ }^{2}$ que según Bejerano (2019), en China se produjo en 2017

\footnotetext{
${ }^{1}$ Rubio (2014:17-18) destacó que la crisis tuvo su génesis en el sector alimentario, la cual estalló en 2008 debido al «dominio agroalimentario de Estados Unidos como eje causal de los campesinos del mundo (...) En los años setenta, al iniciar el declive hegemónico de Estados Unidos en el plano económico, los alimentos se convirtieron en uno de los elementos estratégicos para recuperar el dominio del mundo».

2 Según Sacchetti (2013:140), se refieren a 30 elementos químicos de la Tabla de Mendelev, también llamada Tabla Periódica de los Elementos, de los cuales 17 son utilizados en los procesos industriales más avanzados, en este caso el escandio, el itrio y los 15 lantánidos: lantano, cerio, praseodimio, neodimio, prometio, samario, europio, gadolinio, terbio, disprosio, holmio, erbio, tulio, iterbio y lutecio.
} 
81 por ciento en el nivel global; y el litio cuyas reservas mundiales son controladas en 80 por ciento por Argentina, Bolivia y Chile (IADE, 2015) para satisfacer el mercado de las energías renovables, aplicado a las industrias aeronáutica, agroalimentaria, electrónica, nuclear y la nanotecnología.

Otro elemento de relevancia geopolítica es la reciente disputa comercial que sostienen China y Estados Unidos por el dominio alimentario y energético a escala global, donde la demanda internacional por las tierras raras extraídas de China a partir de 2011 y 2012 se configuró como un problema económico emergente por la dependencia de las principales economías del mundo hacia la demanda de estos minerales. Según Sacchetti, en China, desde finales del siglo XX, ya estaba este tema en la agenda pública de los encargados de la toma de decisiones: «En el año 1992, el expresidente de la Comisión Militar Central de la República Popular de China (1981-1989), Deng Xiaoping, afirmó que «si el Medio Oriente tiene el petróleo, China tiene las tierras raras»» (2013:138); lo que significaría que la extracción y beneficio de las tierras raras apuntan a convertirse en el siglo XXI en un problema agrario emergente que amenaza la justicia ambiental y social en los territorios rurales en particular del Sur global, aunque de acuerdo con Padró y Marco (2015) también aparece el mismo riesgo en territorios de China, Estados Unidos, Australia, Vietnam y la Unión Europea.

En el planteamiento del problema se destaca que en México, al igual que en Centroamérica y la mayor parte de América Latina, el Estado ha fijado como objetivo prioritario el crecimiento económico con la ilusión de promover el desarrollo nacional y la generación de empleos e inversiones. Para ello ha encauzado un proyecto nacional de corte extractivista, convirtiéndose en gestor del capital privado transnacional que participa en la megaminería con emprendimientos de gran escala, que han favorecido el despojo 
territorial que impide la justicia ambiental en los pueblos originarios y comunidades campesinas donde se instala dicha industria. Los efectos se han manifestado en la exploración, explotación y beneficio de metales preciosos en los territorios con abundancia de minerales, hecho que contribuye al incremento de la pobreza; además, el agotamiento de los recursos naturales dificulta el acceso sostenible hacia los mismos. Paralelamente, la legislación ambiental vigente y las prácticas de corrupción, mediante distintos mecanismos de subordinación de México hacia los Estados nacionales de las economías del Norte global, principalmente Canadá y Estados Unidos, favorecen al lobby internacional minero, como quedó legalmente establecido en el año 1992 en la reforma al artículo 27 constitucional y en el artículo 6 de la Ley Minera, que concibe a la minería como una actividad pública preferente por encima de cualquier otra actividad productiva del país.

Lo anterior ha significado un proceso intensivo de privatización del territorio mexicano, cuya tendencia ha sido el acaparamiento de tierras por empresas mineras de capital privado transnacional que bajo la modalidad de concesiones se han apropiado de más de la mitad de la superficie del suelo mexicano. Dichas empresas con su actuar vulneran los derechos humanos en las comunidades donde se instalan y provocan diversos problemas de contaminación, violencia y saqueo de recursos naturales, que a su vez detonan en el surgimiento de conflictos socioambientales y acciones colectivas de resistencia de las comunidades campesinas e indígenas afectadas por la megaminería.

Las principales investigaciones que analizaron la relación entre megaminería, justicia ambiental y derechos humanos en México resaltaron los trabajos de Cortez (2008), quien aborda la criminalización que instrumenta el Estado mexicano en respuesta a las acciones colectivas de resistencia 
que defienden derechos sociales y económicos afectados por la megaminería, con más fuerza a partir de las reformas estructurales implantadas en la década de 1990 (Gutiérrez, 2010). Por su parte, Garibay y Balzaretti (2009) destacaron los planteamientos conceptuales acerca de la reciprocidad negativa, y Garibay (2010) hizo énfasis en la acumulación minera por desposesión campesina a través de la injusticia ambiental y reparto desigual de la renta minera; por ejemplo, en comunidades con megaproyectos mineros solamente se quedan con 18 centavos de cada mil dólares, en la empresa Goldcorp en Zacatecas (Journal of Latin American Geography, 2011); en Guerrero, Patiño et al. (2012) y Cárdenas (2013) revisaron los impactos ecosociales y desafíos a los derechos humanos donde existe la megaminería; Tetreault (2013a), y Santacruz y Peña (2013) analizaron la contaminación de agua y la generación de residuos sólidos por la industria minera.

Toledo (2015) examinó la afectación del ecosistema y la vulneración de los derechos humanos campesinos por empresas de capital transnacional que participan en la industria minera y otros megaproyectos extractivos. Torres (2015) señaló que, desde la economía política ecológica, debe reforzarse el pensamiento crítico, que permita hacer compatibles los derechos humanos con los derechos de la naturaleza y así evitar lo que planteó Azamar (2016) sobre la mercantilización de los derechos humanos. Bellota (2017) estudió el despojo territorial de la megaminería y afectaciones a los derechos indígenas mediante evidencia empírica con los huicholes en territorio de Wirikuta. En Guzmán (2018a y 2018b) se planteó el concepto acumulación minera por extracción de derechos humanos, donde la extracción y beneficio de minerales implica vulnerar los derechos civiles, políticos, económicos, sociales y culturales. 
Las investigaciones realizadas previamente en México contribuyeron a esbozar la problemática de injusticia ambiental y de vulneración de los derechos humanos donde se practica la megaminería; no obstante, no se contaba con una revisión integral concreta de alcance en la escala nacional. En ese sentido, la contribución principal de este estudio consiste en ofrecer un mapeo exploratorio integral preliminar sobre la injusticia ambiental y la forma en que las empresas que practican la megaminería en México vulneran lo que establece la Declaración Universal de Derechos Humanos, analizado en el contexto de Centroamérica.

La técnica de investigación aplicada fue la observación indirecta para ofrecer un panorama exploratorio indicativo sobre la relación entre megaminería, justicia ambiental y derechos humanos en México. Se analizó información teórica y evidencia empírica obtenida de fuentes bibliográficas y hemerográficas recabada en 2019. En el análisis de la información se consideraron dos tipos de variables vinculadas a la megaminería: justicia ambiental y derechos humanos, ambas con datos agregados a escala nacional en el contexto de América Central. En cuanto a justicia ambiental se incluyeron indicadores socioeconómicos: índice de planeta feliz, acaparamiento de tierras, índice de agotamiento de los recursos naturales, disponibilidad de minerales metálicos — principalmente oro y plata, los cuales se complementaron con datos de ingreso nacional bruto-, pobreza e índice de desarrollo humano. En el análisis de los derechos humanos se incluyeron: derechos civiles, derechos políticos, derechos económicos, sociales y culturales y derechos de solidaridad o de los pueblos, y se tomó como referencia lo que señala la Declaración Universal de Derechos Humanos.

La pregunta es ¿cómo se manifiesta la justicia ambiental y los derechos humanos en los territorios donde intervienen megaproyectos mineros de 
capital privado trasnacional? En la hipótesis se plantea que la megaminería en México en manos del capital privado transnacional durante el periodo neoliberal ha significado una dinámica de despojo territorial, que se traduce en injusticia social y vulneración de los derechos humanos, con afectaciones a la vida humana y natural.

La investigación se estructuró en dos apartados, en el primero se presenta la problemática que se genera por la falta de justicia ambiental en México, y en el segundo los impactos en los derechos humanos de las comunidades afectadas por la megaminería.

\section{Los signos vitales de la injusticia ambiental por la megaminería en el territorio mexicano}

Sobre las condiciones materiales que prevalecen en el área de estudio, primeramente se destaca que México, según el Instituto Nacional de Estadística y Geografía (INEGI) (2015), cuenta con una población de 119 millones 938 mil 473 habitantes. En términos geográficos, su territorio (con abundancia en materias primas minerales que han sido explotadas durante cinco siglos) está dividido en 32 entidades federativas, y cuenta con una superficie de un millón 964 mil 375 kilómetros cuadrados. México forma parte de la región de América del Norte, y en su articulación económica tiene como principales socios comerciales a Estados Unidos y Canadá a través del Tratado de Libre Comercio de América del Norte (TLCAN), vigente para el periodo 1994-2018, que durante el mes de diciembre de 2019 se renegoció por otros 16 años más la versión 2.0 de dicho acuerdo comercial, ahora Tratado entre México, Estados Unidos y Canadá (T-MEC). 
Para explicar cómo se manifiesta la influencia de la megaminería en limitar el derecho de los mexicanos a un medio ambiente sano, a la justicia ambiental y la equidad social, se plantean nueve elementos, los cuales son revisados en el contexto de América Central, por la hermandad que tiene México con otras naciones de la región que forman parte del Sur global, donde se producen las mayores afectaciones de los megaproyectos extractivos de la industria minera. De acuerdo con Darcy Tetreault (2013b:192), Canadá se convirtió en el país hegemónico en dicho sector económico a escala global, mediante el impulso de una estrategia integral de intervención financiera, legislativa, económica y diplomática en el Sur global y con mayor peso en América Latina, sobre todo porque

tres cuartas partes de las empresas mineras en el mundo tienen sus oficinas centrales en Canadá y casi 60 por ciento están registradas en la Bolsa de Valores de Toronto. Estas compañías representan cerca del 40 por ciento de la inversión mundial en exploración minera en el mundo, (...) más de la mitad de los activos de las mineras canadienses se ubica en América Latina.

1. Disponibilidad de oro y plata. Según el Consejo Mundial del Oro (2019), entre los 10 principales países productores de oro a escala global, entre todas las naciones de América Central únicamente aparece México, mismo que se ubica en el décimo lugar en cuanto a mayor producción de oro; para el año 2018 extrajo 115.4 toneladas, equivalente al 3.4 por ciento de la producción mundial, mientras que el primer lugar lo obtuvo China con 404.1 toneladas, equivalente al 12.1 por ciento. Asimismo, los datos de Silver Institute (2019) indicaron que para 2018, de las naciones de América Central, sólo México apareció entre las 10 principales naciones 
productoras de plata y se ubicó en el primer lugar mundial de producción de dicho metal precioso con 196.6 millones de onzas, equivalente a 22.9 por ciento del total global.

2. Ingreso Nacional Bruto per cápita. Los datos de la Organización Panamericana de la Salud (OPS)-Organización Mundial de la Salud (OMS) (2018) indicaron que en el ingreso nacional bruto per cápita México ocupó el segundo lugar de Centroamérica en 2017 con 17 mil 740 dólares, lo que representa casi el doble del promedio de América Central, el cual fue por la cantidad de 8 mil 995 dólares. Mientras que el resto de naciones de dicha región en este rubro se ubicaron de la siguiente manera: Panamá primero, Costa Rica tercero, Guatemala cuarto, Belice quinto, El Salvador sexto, Nicaragua séptimo y Honduras octavo lugar.

3. Pobreza. De acuerdo con la Comisión Económica para América Latina y el Caribe (Cepal) (2018), México cuenta con 50.6 por ciento de su población en situación de pobreza, hecho que lo coloca en el segundo lugar de América Central, muy por encima de 36 por ciento alcanzado en dicha región. Por su parte, Honduras se situó en el primer lugar de la región (65.7 por ciento), El Salvador en el tercero (32.7 por ciento), Nicaragua en el cuarto (24.9 por ciento), Panamá en el quinto (22.1 por ciento) y Costa Rica en el sexto (20.5 por ciento).

Asimismo, al revisar lo que ocurre con la situación de pobreza a escala local, en FUNDAR Centro de Análisis e Investigación (2018:180) se indicó que 62 por ciento de los municipios mexicanos productores de oro superaron el nivel promedio de pobreza que existe a escala nacional, y 42 por ciento superó el nivel promedio de pobreza extrema; mientras que 80 por ciento de los municipios productores de plata en México superaron el nivel de pobreza nacional y 47 por ciento el nivel de pobreza extrema que prevalece en el país. 
4. Índice de Desarrollo Humano. Con base en el Programa de las Naciones Unidas para el Desarrollo (PNUD) (2018), México contó con 0.774 en el Índice de Desarrollo Humano y se ubicó en el tercer lugar de la región de América Central que alcanzó un promedio de 0.708; las otras naciones de la región quedaron de la siguiente manera: primero, Costa Rica; segundo, Panamá; cuarto, Belice; quinto, El Salvador; sexto, Nicaragua; séptimo, Guatemala; y Honduras en octavo lugar.

5. Índice de planeta feliz. En Happy Planet Index (2016) se apuntó que México contaba con 40.7 puntos en el Índice de Planeta Feliz, ello lo convierte en el segundo mejor calificado de América Central y a escala mundial después de Costa Rica, situado en primer lugar tanto de la región de América Central como del mundo con 44.7 puntos; Panamá ocupó el tercero, Nicaragua el cuarto, El Salvador el quinto, Guatemala el sexto, Belice el séptimo y Honduras el octavo lugar de América Central.

6. Acaparamiento de tierras. A partir de los datos disponibles en Abad (2018), Trucchi (2016) y Nolasco (2011), se estima que en Centroamérica un millón 246 mil 990 kilómetros cuadrados de superficie de territorio fueron concesionados a la industria minera, de los cuales, de acuerdo con información pública del gobierno de México, disponible en Semarnat (2012) y la Secretaría de Economía (2016 y 2019), indican que en el territorio mexicano se ubica 91.9 por ciento de dicha superficie, equivalente a un millón 146 mil 710 kilómetros cuadrados; mientras que en Honduras se concesionó 35 por ciento, en Guatemala 30 por ciento, en Nicaragua 13.5 por ciento y en Panamá 18 por ciento del territorio nacional de cada país, respectivamente.

7. Índice de agotamiento de los recursos naturales. Conforme al Banco Mundial (2019), México predomina como el país en la región de América Central con el mayor agotamiento de los recursos naturales durante el 
periodo neoliberal, específicamente en los 35 años de 1982-2017 que se registró un promedio anual de 3.2 por ciento, equivalente a más del doble de Centroamérica, que apenas alcanzó 1.4 por ciento debido a que Belice y Honduras obtuvieron 1.1 por ciento, Guatemala 1.3 por ciento, El Salvador 0.7 por ciento, Nicaragua 1.9 por ciento y Costa Rica 1.8 por ciento.

8. Índice de percepción de la corrupción. Según Transparency International (2018), en un rango sobre 180 países, México se colocó en el lugar 138 a escala global y en el tercero de América Central, superior a 122.5, promedio de dicha región; Nicaragua se ubicó en primero, Guatemala en segundo, Honduras en cuarto, El Salvador en quinto, Panamá en sexto y Costa Rica en séptimo lugar.

9. Conflictos socioambientales y litigios internacionales. El Environmental Justice Atlas (Ejatlas) (2019) confirmó que para el mes de diciembre de 2019 se tenían registrados 3 mil 2 conflictos socioambientales a escala planetaria, México ubicado en el sexto lugar mundial, con un total de 108 conflictos registrados. Adicionalmente, al revisar los datos de América Central, México se colocó en el primero de la región con 108 casos, Guatemala en segundo con 27, Honduras en tercero con 20, Costa Rica en cuarto con 18, Panamá en quinto con 17, Nicaragua en sexto con 11, El Salvador en séptimo con 6 y Belice en octavo con 4 casos, respectivamente. Un dato relevante es que de los 62 conflictos socioambientales registrados en Centroamérica ligados a la industria minera, 35 se situaron en México, equivalente a 56.4 por ciento del total de la región.

Otra información de contraste es que de acuerdo con el Observatorio de Conflictos Mineros de América Latina (OCMAL) (2019), al mes de diciembre de 2019 se registró un total de 275 conflictos mineros en América Latina, de los cuales 84 se localizaron en Centroamérica: México (49), 
Guatemala (10), Nicaragua (7), Panamá (7), Honduras (6), El Salvador (3) y Costa Rica (2), dichas cifras corroboran que México concentró 58.3 por ciento de los conflictos mineros ocurridos en Centroamérica.

Otra de las disputas territoriales por la megaminería se lleva a cabo en tribunales internacionales, los datos del Centro Internacional de Arreglo de Diferencias Relativas a Inversiones (CIADI) (2019a y 2019b), adscrito al Banco Mundial, indicó que a escala global se tenían 267 litigios en proceso (39 se refieren a la minería), de ellos uno corresponde a México y 476 concluidos (124 se refieren a la minería). Asimismo, en Garay (2014) y Moore y Pérez (s/f) se destacó que para 2019, las empresas mineras de capital privado transnacional han tramitado litigios internacionales en contra de Estados nacionales de Centroamérica por un monto de 5 mil 404.3 millones de dólares, de los cuales 4 mil 40 (equivalente a 74.7 por ciento) correspondían a México, 475 millones de dólares a El Salvador, 321 millones de dólares a Costa Rica, 300 millones de dólares a Guatemala y 268.3 millones de dólares a Panamá.

\section{Los impactos de la megaminería en los derechos humanos en México}

El Estado mexicano amplió la apertura a la inversión de capital privado transnacional a partir de las reformas al artículo 27 de la Constitución Política de los Estados Unidos Mexicanos, así como a la Ley Agraria y a la Ley Minera impulsadas durante la década de 1990, que facilitaron la privatización de tierras que estaban en la modalidad de propiedad social; al igual que ocurrió con la nueva legislación minera en otras naciones de 
Centroamérica, tal como puntualizó Martínez (2019) en los casos de Guatemala en 1997, Costa Rica en 1998, Honduras en 1998 y 2013, Panamá en 2011 y El Salvador en 2012. Dicha base legal brindó seguridad jurídica a la inversión minera, a la par que agudizó el agotamiento de los recursos naturales y la violación a los derechos humanos; lo que ocasionó que en las comunidades afectadas y como respuesta de los actores, recurrieran a la defensa del territorio, mientras que las empresas de capital privado han llevado mecanismos de control político y diplomático, a la par de litigios en tribunales nacionales e internacionales como medida para contrarrestar las acciones colectivas de resistencia.

Sobre la vulneración a los derechos humanos a continuación se presenta un esbozo clasificado en cuatro rubros a partir de lo que dispone la Declaración Universal de Derechos Humanos. De acuerdo con Amnistía Internacional (2019), México destaca en la región de América Central por la vulneración a los derechos humanos por razones de violencia extrema, impunidad, refugiados, defensores de medio ambiente y feminicidios.

1. Vulneración de derechos civiles. La industria minera ha generado afectación a los derechos humanos de la dignidad, igualdad, a la vida, libertad y seguridad, que según la Comisión Nacional de los Derechos Humanos (CNDH) (2016) se reflejaron en las 150 mil víctimas desplazadas por proyectos extractivos en México.

Otros datos de referencia según el Independent Data Monitoring Committee (IDMC) (2018) evidencian 34 mil personas afectadas por desaparición forzada (incluidos los 43 estudiantes de Ayotzinapa, Guerrero), así como 338 mil desplazados internos por conflicto y violencia en el territorio mexicano, que en situación extrema ha implicado también discriminación, represión policiaca a manifestaciones indígenas, amenazas de 
muerte y hostigamiento militar, hasta la pérdida de vidas humanas, como ocurrió con los 65 mineros muertos en San Juan de Sabinas, Coahuila, en la Unidad Minera Pasta de Conchos de Grupo México, al igual que en el año 2012 el asesinato de 35 ejidatarios en los estados de Colima y Jalisco.

El desplazamiento interno en otros países de América Central fue del siguiente modo: El Salvador 246 mil, Guatemala 242 mil, Honduras 190 mil, Nicaragua 6 mil 900 y Costa Rica 5 mil 800 desplazados, respectivamente. En una mirada de conjunto, los datos empíricos anteriores demuestran que en México se presentó 32.8 por ciento de los 1 millón 28 mil 700 casos de personas afectadas por desplazamiento interno acaecidos en América Central.

Otros datos empíricos de referencia conforme al Global Witness (2019), entre los 19 países del mundo que durante el 2018 reportaron el mayor número de ambientalistas asesinados destacaron tres naciones de América Central: Guatemala ocupó el quinto lugar con 16 asesinatos, México el sexto lugar con 14 asesinatos y Honduras el noveno lugar con cuatro asesinatos. Referente al número de asesinatos por sector productivo, la minería e industrias extractivas encabezó la lista con un total de 43 casos.

2. Afectación de derechos políticos. No se cuenta con una clara impartición de justicia en materia ambiental debido a la violación de los derechos políticos como el ser oído públicamente, la no injerencia en la vida privada y el domicilio, la circulación libre por el territorio, tal y como ocurrió con las 57 mil personas refugiadas de Guatemala, El Salvador y Honduras quienes pidieron asilo político en el extranjero, en su mayoría en México (Amnistía Internacional, 2019).

Sin embargo, no todo está perdido, pues existe un recurso efectivo en tribunales, aunque regularmente los ganan las empresas mineras 
transnacionales, con excepción de un caso que ocurrió en 2009 contra la empresa minera canadiense Goldcorp, por un monto de 3 millones de dólares por año a favor de los ejidatarios de Cedros del municipio de Mazapil, Zacatecas (Guzmán, 2018a). Este tipo de experiencia debería sentar precedente para fortalecer la defensa del territorio en comunidades afectadas por la megaminería, debido a que en 2017 se contaba con un registro de 25 mil 506 títulos de concesión minera sin consultar a las comunidades (Geocomunes, 2017); además del control corporativo que ejercen las empresas mineras en contubernio con los gobiernos para debilitar el derecho a la reunión y asociación pacíficas mediante mecanismos de rupturas sindicales.

3. Quebrantamiento de derechos económicos, sociales y culturales. La industria minera ha generado afectaciones al derecho a la propiedad, al acaparar tierras y destruir medios de vida en comunidades campesinas e indígenas en México; aunque también hay casos de resistencia que han cancelado operación y han declarado territorios libres de minería, como ocurrió en los estados de Colima, San Luis Potosí y Chiapas. Otro tipo de afectación es que la vida de un trabajador minero en México se estima en 45 años promedio, mientras que a escala mundial alcanza hasta los 55 años (El Universal, 2011).

Asimismo, según el INEGI (2009) 45.4 por ciento de los trabajadores mineros fueron subcontratados sin derechos laborales y sujetos a sobreexplotación cumpliendo jornadas atípicas de hasta 12 horas diarias por un periodo de 14 días consecutivos. Todo ello aunado a la destrucción de las culturas rurales y la salud humana en las comunidades mineras, como ocurrió con los derrames tóxicos que afectaron a 502 mil habitantes en los estados de Sonora y Zacatecas (Guzmán, 2018a). 
Concerniente a Centroamérica un par de casos representativos acerca de la afectación a la salud pública, de acuerdo con Rel Uíta, se presentó en el «Valle de Siria, en Honduras, y de San Miguel Ixtahuacán, en Guatemala, donde la explotación minera dejó graves problemas de la piel, partos prematuros, malformaciones congénitas, abortos, pérdida de la vista y caída del pelo» (2014:10).

4. Infracción de derechos de solidaridad o de los pueblos. Las mineras violan el derecho a la consulta pública, libre, previa e informada en las comunidades, establecido en el convenio 169 de la Organización Internacional del Trabajo (ОIT), principalmente porque los acuerdos comerciales entre naciones, como acaeció con el TLCAN ahora T-MEC, contemplan cláusulas que favorecen los derechos corporativos de las empresas de capital transnacional. Asimismo, se vulneran los derechos de solidaridad y cooperación comunitaria por la distribución desigual de aplicación de recursos públicos para el desarrollo comunitario, tal como aconteció con los 6 mil 792.3 millones de pesos designados durante los ejercicios fiscales de 2014 a 2016 a través del Fondo para el Desarrollo Regional Sustentable de Estados y Municipios Mineros (Guzmán, 2018b).

En este rubro, conforme a datos de Amnistía Internacional (2019), destacó también la violación a los derechos humanos de los pueblos indígenas en naciones de América Central, por ejemplo, Honduras y Nicaragua; así como el riesgo extremo que significa para los periodistas y defensores de los derechos humanos y el medio ambiente ejercer su labor social en países como Honduras, México y Nicaragua. Además, Acafremin (2019) indicó que la Unión Internacional para la Conservación de la Naturaleza (UICN) en el año 2016 confirmó que en América Central existen 70 pueblos originarios de diversas etnias, aunado a que 40 por ciento de las áreas 
naturales protegidas de la región está traslapada con tierras indígenas en convivencia sostenible y armónica con la naturaleza; sin embargo, las concesiones mineras vulneraron los derechos humanos individuales y colectivos, en particular en Guatemala y El Salvador.

Otra afectación derivada de la megaminería es el derecho humano al agua, según Cartocrítica (2016) y Conagua (2016) en México se concesionaron 436 millones 643 mil 287.92 metros cúbicos de agua, equivalente a la requerida para garantizar este derecho a 11 millones 962 mil 830 personas por año, cifra aproximada a la población de cuatro entidades federativas: Ciudad de México, Campeche, Colima y Nayarit.

El fenómeno de la megaminería en Mexico, a partir de la década de 1980 con el surgimiento del modelo neoliberal, derivó en violaciones a los derechos consagrados en la Declaración Universal de Derechos Humanos. En consecuencia, con las reformas estructurales instrumentadas en la década de 1990, derivadas de las políticas de ajuste impuestas a México y otras naciones de América Central por organismos internacionales como el Fondo Monetario Internacional y el Banco Mundial, tendientes a la privatización de los bienes públicos, dicha problemática se agudizó a causa de las cláusulas desfavorables plasmadas en los acuerdos comerciales como el TLCAN.

Como resultado de lo anterior, los efectos se manifestaron en la permanencia de la pobreza, la destrucción de los bienes comunes naturales de la nación y el acaparamiento de tierras para la minería, disfrazado legalmente mediante el otorgamiento de concesiones de exploración y explotación mineras, sumado a la flexibilidad en la aplicación de la legislación vigente en la materia; ello ha desencadenado actos de corrupción e impunidad, derechos humanos transgredidos y conflictos socioambientales. En ese sentido, siguiendo a la Federación Iberoamericana del Ombudsman 
(FIO), la Deutsche Gesellschaft für Internationale Zusammenarbeit (GIZ) y la Cepal (2019), es significativo que los Estados nacionales de la región de América Central adopten el enfoque de derechos humanos en los procesos de evaluación de impacto ambiental y que las empresas mineras de capital privado establezcan políticas internas de salvaguarda de los derechos humanos en los territorios de las comunidades intervenidas por megaproyectos extractivos, durante las distintas fases de la extracción y beneficio de minerales.

Estudios previos de Garibay y Balzaretti (2009), Tetreault (2013a), Santacruz y Peña (2013) atienden por separado la relación megaminería y justicia ambiental, a partir de los impactos ecosociales que esta industria extractiva genera; por su parte, los análisis de Cortez (2008), Patiño et al. (2012), Cárdenas (2013), Toledo (2015), Torres (2015), Azamar (2016), Bellota (2017) y Guzmán (2018a y 2018b) se enfocan en la manera en que la industria minera vulnera los derechos humanos, principalmente el derecho a la salud, al trabajo, a la propiedad, al agua, a la alimentación y al libre tránsito. En la presente investigación se logró generar un panorama integral que permitió explicar la relación megaminería, derechos humanos y justicia ambiental, con base en la información empírica de México vista en el contexto de la escala internacional en una región del Sur global como el caso de América Central.

\section{Conclusiones}

Los resultados preliminares de esta investigación, al poner a prueba la hipótesis planteada permitió mencionar que la megaminería en México practicada durante el periodo neoliberal (1982-2019) ha vulnerado los 
derechos humanos y propiciado la injusticia ambiental en los territorios de comunidades donde opera. Dicha dinámica se agudizó a partir de la década de 1990 con las reformas estructurales implementadas y con el TLCAN puesto en marcha desde 1994. Lo anterior posibilitó que para el Estado mexicano los derechos corporativos de las empresas de capital privado transnacional estén por encima de los derechos humanos que establece la Declaración Universal de Derechos Humanos.

A pesar de la disponibilidad de minerales metálicos y de que la minería sea una actividad pública preferente, México se ubica en el primer lugar mundial en la extracción de plata y en el décimo lugar de oro. Adicionalmente, México reporta mejores resultados que el promedio de América Central en cuanto a ingreso nacional per cápita, índice de desarrollo humano e índice de planeta feliz.

Este panorama contrasta paradójicamente con que México, en el contexto de Centroamérica, también se ubicó entre las naciones con mayor porcentaje de su población en situación de pobreza, que en la actualidad afecta a 5 de cada 10 mexicanos; aparte de que 9 de cada 10 kilómetros cuadrados de concesiones mineras de Centroamérica se ubicaron en territorio mexicano, aunado a que México es el país centroamericano con el más alto índice de agotamiento de los recursos naturales.

Asimismo, en cuanto a percepción de la corrupción, México se ubicó entre los países con más corrupción de América Central; sin soslayar que concentra la mitad de los conflictos socioambientales por megaproyectos mineros en Centroamérica, incluso 7 de cada 10 dólares del monto de litigios internacionales mineros en dicha región se han promovido en contra del Estado mexicano. De modo complementario, México destacó por los impactos de la industria minera en cuanto a la violación de los derechos humanos. 


\section{FEDERICO GUZMÁN LÓPEZ}

En síntesis, es prioritario promover un diálogo nacional que ponga en el centro de la discusión transitar de los diagnósticos y de la protesta, hacia la propuesta sobre la construcción social de otro desarrollo posible en torno a la megaminería. En dicho proceso reviste especial importancia la intervención de las instituciones académicas y de investigación científica para promover acciones colectivas tendientes a detonar mecanismos de consulta pública, libre, previa e informada, donde participe la población y las organizaciones de la sociedad civil en programas y presupuestos públicos que enfaticen en torno a la justicia ambiental y la salvaguarda de los derechos humanos.

\section{Referencias}

Abad, C. (2018). «Extractivismo monumental e intervención faraónica». La Estrella. Recuperado de http://laestrella.com.pa/panama/nacional/ extractivismo-monumental-intervencion-faraonica/24068514

Acafremin (2019). «Concesiones mineras violentan múltiples derechos a pueblos indígenas y tribales en Centroamérica». Ocmal. Recuperado de https:// www.ocmal.org/concesiones-mineras-violentan-multiples-derechos-apueblos-indigenas-y-tribales-en-centroamerica/

Amnistía Internacional (2018). «América 2017/2018». Recuperado de https:// www.amnesty.org/es/countries/americas/report-americas/

Azamar, A. (2016). Acumulación originaria: explotación laboral y generación de ganancia en la minería de México (tesis doctoral). Madrid: Universidad Complutense de Madrid. Recuperado de https://eprints.ucm.es/40577/ 
Banco Mundial (2019). «Ahorros reajustados: agotamiento de los recursos naturales (\% del INB)». Recuperado de https://datos.bancomundial.org/ indicador/NY.ADJ.DRES.GN.ZS

Bellota, L.A. (2017). La megaminería en México: devastación ecológica y despojo territorial. Ciudad de México: Centro de Estudios Sociales y de Opinión Pública/Cámara de Diputados, LXIII Legislatura. Recuperado de http://www5. diputados.gob.mx/index.php/camara/Centros-de-Estudio/CESOP/Estudiose-Investigaciones/Documentos-de-Trabajo/Num.-237-La-megamineria-enMexico-devastacion-ecologica-y-despojo-territorial

Cárdenas, J. (enero-junio, 2013). «La minería en México. Despojo a la nación». Cuestiones Constitucionales. Revista Mexicana de Derecho Constitucional (28). Recuperado de http://www.scielo.org.mx/pdf/cconst/n28/n28a2.pdf

Cartocrítica (2016). «Concesiones de agua para las mineras». Cartocrítica. Recuperado de http://www.cartocritica.org.mx/2016/concesiones-de-agua-para-las-mineras/ Comisión Económica para América Latina y el Caribe (Cepal) (2018). «Panorama Social de América Latina 2018». Recuperado de https://repositorio.cepal. org/bitstream/handle/11362/44395/11/S1900051_es.pdf

Centro Internacional de Arreglo de Diferencias relativas a Inversiones (CIADI) (2019a). «Pending cases with details». Recuperado de https://icsid.worldbank.org/sp/Pages/cases/pendingCases.aspx?status=p

Centro Internacional de Arreglo de Diferencias relativas a Inversiones (CIADI) (2019b). «Concluded cases with details». Recuperado de https://icsid. worldbank.org/sp/Pages/cases/ConcludedCases.aspx?status=c

Comisión Nacional de los Derechos Humanos (CNDH) (2016). «Informe especial sobre desplazamiento forzado interno (DFI) en México». Ciudad de México: CNDH. Recuperado de http://gaceta.diputados.gob.mx/Gaceta/63/2016/ may/Cndh-20160523.pdf 


\section{FEDERICO GUZMÁN LÓPEZ}

Comisión Nacional del Agua (Conagua) (2016). «Títulos y volúmenes de aguas nacionales y bienes inherentes por uso de agua». Recuperado de http://www. conagua.gob.mx/CONAGUA07/Contenido/Documentos/nacional.pdf

Consejo Mundial del Oro (2019). «Producción de minas de oro». Recuperado de https://www.gold.org/goldhub/data/historical-mine-production

Cortez, E. (julio-agosto, 2008). «Criminalización de la protesta social en México». El Cotidiano, 23(150), pp. 73-76. Recuperado de http://www.redalyc.org/ articulo.oa?id=32515011

El Universal (2011). «La oscura vida del minero». Recuperado de http://Archivo. Eluniversal.Com.Mx/Editoriales/52845.Html

Ejatlas (2019). «Países». Recuperado de https://ejatlas.org/country

Federación Iberoamericana de Ombudsman (FIO), Sociedad Alemana de Cooperación Internacional (GIZ) y Comisión Económica para América Latina y el Caribe (CEPAL) (2019). «Recomendaciones para la incorporación del enfoque de derechos humanos en la evaluación de impacto ambiental de proyectos mineros». Recuperado de https://repositorio.cepal.org/bitstream/ handle/11362/44955/1/S1901074_es.pdf

FUNDAR. Centro de Análisis e Investigación (2018). Las actividades extractivas en México. Desafíos para la 4T, Anuario 2018. Ciudad de México: FUNDAR.

Garay, A. (2014). «La minería transnacional en Centroamérica: lógicas regionales e impactos transfronterizos. El caso de la mina Cerro Blanco». Recuperado de http://omal.info/IMG/pdf/mineria_transnacional.pdf

Garibay, C. y Balzaretti, A. (mayo-agosto, 2009). «Goldcorp y la reciprocidad negativa en el paisaje minero de Mezcala, Guerrero». Desacatos. Revista de Antropología Social (30), pp. 91-110. Recuperado de http://www.scielo.org. $\mathrm{mx} / \mathrm{pdf} /$ desacatos/n30/n30a7.pdf 
Garibay, C. (2010). «Paisajes de acumulación minera por desposesión campesina en el México actual». En Delgado, G.C. (coord.) (2010), Ecología política de la minería en América Latina (pp. 133-182). México: Centro de Investigaciones Interdisciplinarias en Ciencias y Humanidades-Universidad Nacional Autónoma de México.

Geocomunes (2017). «Amenaza neoliberal a los bienes comunes: panorama nacional de megaproyectos mineros». Recuperado de http://geocomunes.org/ Analisis_PDF/Mineri\%CC\%8la\%20A\%20lectura

Global Witness (2019). «¿Enemigos del Estado? De cómo los gobiernos y las empresas silencian a las personas defensoras de la tierra y del medio ambiente». Recuperado de https://www.globalwitness.org/es/campaigns/ environmental-activists/enemigos-del-estado/

Gutiérrez, R. (2010). «Apropiación minera y violación de derechos humanos en México». En Delgado, G.C. (coord.), Ecología politica de la minería en América Latina (pp. 281-298). México: Centro de Investigaciones Interdisciplinarias en Ciencias y Humanidades-Universidad Nacional Autónoma de México.

Guzmán, F. (2018a). Megaminería y 7 maldades del despojo territorial. Berlín: Editorial Académica Española.

Guzmán, F. (mayo-agosto, 2018b). «Acumulación minera por extracción de derechos humanos». Observatorio del Desarrollo, 7(20). Recuperado de https:// www.estudiosdeldesarrollo.mx/observatorio/ob20/7.pdf

Happy Planet Index (2016). «Happy Planet Index». Recuperado de http://happy planetindex.org/about

Internal Displacement Monitoring Centre (IDMC) (2018). «2018. Cifras de desplazamiento interno por país». Recuperado de http://www.internal-displacement. org/database/displacement-data 


\section{FEDERICO GUZMÁN LÓPEZ}

Instituto Nacional de Estadística y Geografía (INEGI) (2009). «Minería». México: INEGI. Recuperado de http://www.inegi.org.mx/est/contenidos/espanol / proyectos/censos/ce2009/pdf/M_mineria.pdf

Instituto Nacional de Estadística y Geografía (INEGI) (2015). «Población». Aguascalientes: INEGI. Recuperado de https://www.inegi.org.mx/temas/ estructura/

Garibay, C., Boni, A., Panico, F., Urquijo, P. y Klooster, D. (2011). «Unequal partners, unequal exchange: Goldcorp, the Mexican state, and campesino dispossession at the Peñasquito Goldmine». Journal of Latin American Geography, 10(2). Recuperado de http://muse.jhu.edu/article/449192

Martínez, M.I. (2019). «El extractivismo minero en América Latina: planteamientos, paralelismos y presunciones desde el caso de Guatemala». Perfiles Latinoamericanos, 27(53). Recuperado de https://perfilesla.flacso.edu.mx/ index.php/perfilesla/article/view/746/877

Moore, J. y Pérez, M. (s/f). "Casino del extractivismo. Las empresas mineras apuestan con la vida de los pueblos y la soberanía de los países de América Latina usando el arbitraje supranacional». Canadá: MiningWatch/Institute for Policy Studies/Center for International Environmental Law. Recuperado de http://www.remamx.org/wp-content/uploads/2019/06/ISDSMining-Latin-America-Report-Formatted-SPANISH.pdf

Nolasco, S. (2011). «Impactos de la minería metálica en Centroamérica». Ocmal. Recuperado de https://www.ocmal.org/wp-content/uploads/2017/03/ Impactos_de_la_Mineria_Metalica_en_Centroamerica.pdf

Ocmal (2019). «Conflictos mineros en México». Recuperado de https://mapa. conflictosmineros.net/ocmal_db-v2/conflicto/lista/02024200

OrganizaciónPanamericanadela Saludy Organización MundialdelaSalud(2018). «Indicadores básicos, situación de salud en las Américas 2018». Recuperado de 
http://iris.paho.org/xmlui/bitstream/handle/123456789/49511/Indicadores Basicos2018_spa.pdf?sequence $=2 \&$ isAllowed $=\mathrm{y}$

Padró, R. y Marco, I. (2015). «Abran las minas, cierren el campo», Dipòsit digital de documents de la UAB. Recuperado de https://ddd.uab.cat/record/171457 Patiño, E.R., Espinoza, M.J. y García, Á. (julio-diciembre, 2012). «Concesiones mineras en tierras ejidales: detrimento de la propiedad social». Revista Iberoamericana para la Investigación y el Desarrollo Educativo (09). Recuperado de https://scholar.google.com.mx/scholar?start=10\&q=concesiones+mineras+en+M\%C3\%A9xico\&hl=es\&as_sdt=0,5

Programa de las Naciones Unidas para el Desarrollo (PNUD) (2018). «Índices e indicadores de desarrollo humano. Actualización estadística de 2018». Recuperado de http://hdr.undp.org/sites/default/files/2018_human_development_ statistical_update_es.pdf

Rel-Uita.org (2014). «Minería en Centroamérica: mitos, paradojas y realidades trágicas». Recuperado de http://www.rel-uita.org/pdfs/20140827_Mineria_ en_Centroamerica_web.pdf

Rubio, B. (2014). El dominio del hambre. Crisis de hegemonía y alimentos. México: Universidad Autónoma Chapingo/Colegio de Postgraduados/Universidad Autónoma de Zacatecas/Juan Pablos Editor.

Santacruz, G. y Javier Peña, F. (2013). «Huella gris y minería: el impacto de extracción de metales en el agua». En Pérez, R., Constantino, R. y Dávila, H. (coords.). Agua, alimentación y bienestar: la huella hídrica como enfoque integral de gestión del agua en México. México: Universidad Autónoma Metropolitana-Xochimilco.

Secretaría de Economía (2016). «Superficie del territorio concesionada para la minería en México en el periodo 2013-2016» (respuesta a la solicitud de información con número de folio 0001000058816 tramitada vía Sistema 


\section{FEDERICO GUZMÁN LóPEZ}

Infomex el día 02 de mayo de 2016). México: Dirección General de Regulación Minera.

Secretaría de Economía (2019). «Superficie del territorio concesionada para la minería en México en el periodo 2016-2018» (respuesta a la solicitud de información con número de folio 0001000013919 tramitada vía Sistema Infomex el día 22 de enero de 2019). México: Dirección General de Regulación Minera.

Secretaría de Medio Ambiente y Recursos Naturales (Semarnat) (2012). «Compendio de Estadísticas Ambientales 2012». Recuperado de http:// dgeiawf.semarnat.gob.mx:8080/ibi_apps/WFServlet?IBIF_ex=D2_ ENERGIA05_02\&IBIC_user=dgeia_mce\&IBIC_pass=dgeia_mce

Silver Institute (2019). «Producción minera». Recuperado de https://www. silverinstitute.org/mine-production/

Tetreault, D. (septiembre, 2013a). «La megaminería en México. Reformas estructurales y resistencia». Letras Verdes, Revista Latinoamericana de Estudios Socioambientales (14). Recuperado de http://revistas.flacsoandes.edu.ec/ letrasverdes/article/view/1045

Tetreault, D. (2013b). «Los mecanismos del imperialismo canadiense en el sector minero de América Latina». Estudios Críticos del Desarrollo, III(4), pp. 191-215. Transparency International (2018). «Índice de percepción de la corrupción 2018». Recuperado de https://www.transparency.org/cpi2018

Trucchi, G. (2016). «Centroamérica. modelo extractivista: el despojo de territorios y la criminalización de la protesta en Centroamérica». Recuperado de https://www.tercerainformacion.es/articulo/internacional/2016/10/20/centroamerica-modelo-extractivista-el-despojo-de-territorios-y-la-criminalizacion-de-la-protesta-en-centroamerica

Toledo, V. (2015). Ecocidio en México. La batalla final es por la vida. México: Grijalbo. 
Megaminería en México en el contexto de América Central

Torres, G.A. (2015). Los senderos de la transición civilizatoria. Texcoco: Departamento de Sociología Rural/Universidad Autónoma Chapingo. 